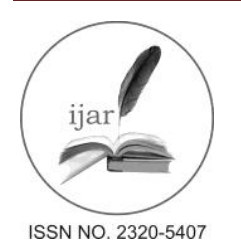

Journal homepage: http://www.journalijar.com

Journal DOI: 10.21474/IJAR01

INTERNATIONAL JOURNAL

OF ADVANCED RESEARCH

RESEARCH ARTICLE

\title{
ENTREPRENEURIAL ORIENTATION AND INNOVATION OF SMALL AND MEDIUM ENTERPRISES IN KANO STATE, NIGERIA.
}

\author{
Lukman T. Siraj ${ }^{1}$, Abuga M Isaac ${ }^{1}$, Kabir Haruna Danja ${ }^{2}$. \\ 1. College of Economics and Management, Kampala International University, Uganda. \\ 2. Department of Business Education,Federal College of Education Zaria, Nigeria.
}

\section{Manuscript Info}

Manuscript History:

Received: 18 March 2016

Final Accepted: 22 April 2016

Published Online: May 2016

Key words:

Entrepreneurial orientation,

innovation, pro activeness SMEs.

*Corresponding Author

Lukman T. Siraj.

\begin{abstract}
This study investigates the role of entrepreneurial orientation in shaping firm innovative performance. A cross sectional survey using questionnaire was conducted on a sample of 261 manufacturing SMEs operating in Kano State, Nigeria. Pearson correlation and linear regression analyses were performed to analyze the data. The results indicate significant relationship between entrepreneurial orientation and firm innovation, and that among the dimensions of entrepreneurial orientation, pro activeness contributes most to innovation. Firms should therefore constantly evaluate the level of their entrepreneurial orientation in order to find out whether it is sufficiently adopted, and that they should concentrate on pro activeness.
\end{abstract}

Copy Right,IJAR, 2016,..All rights reserved.

\section{Introduction:-}

Remarkable transformation of the market place has taken place which emanates from globalization and explosion of information technology (Wang and Huang, 2011). This has made business environment to become uncertain and complex. Market and customer needs therefore change constantly and rapidly. In response to this situation, there have been unprecedented global upsurges in innovation (Gunawan et al; 2013). Acquisition of both technological and non-technological innovations has therefore become the key to guaranteeing competitiveness both at the enterprises level and the national level (OECD, 2005). Thus, enterprises, and equally government, all the world over, are searching and encouraging innovations that will enhance their competitiveness and survival, and devoting and marshalling funds, efforts, time and personnel at the search for new technologies. Such new technologies or innovations are most easily commercialized through Small and Medium Enterprises.

Entrepreneurial orientation is one of the dynamic measures that can spark innovation and enable firms to break the status quo and leapfrog towards superior innovation (Wiklund and Shepered, 2005).Though large amount of researches on entrepreneurial orientation have been conducted,few of such researches have been conducted in Nigeriaparticularly on SMEs.In view of the foregoing however, this study aimed at investigating the relationship that exists between entrepreneurial orientation and innovation of small and medium enterprises.

\section{Literature review:-}

Despite of the large amount of studies examining Entrepreneurial orientation, there are still various debates about it, the forces driving it, its appearance and about the connection between Entrepreneurial orientation and firm innovation (Miller, 2011). One of the topics of the ongoing debates is the definition of entrepreneurial orientation. There is no one widely accepted conceptualization of this latent construct by the scholarly community, but rather different degrees of acceptance for certain conceptualizations (Covin and Lumpkin, 2011).Different well-known definitions that have been used for Entrepreneurial orientation are those of Miller (1983)or Covin and Slevin (1991) 
on one hand, and that of Lumpkin and Dess (1996) on the other hand. Miller (1983) or Coving and Slevin (1991) definition is based on the aspects of innovativeness, risk-taking and pro activeness. Lumpkin and Dess (1996), on the other hand, describe Entrepreneurial orientation as the propensity to act autonomously, innovate, take risks, and act proactively when confronted with market opportunities. These definitions represent the two most widely used bases for perceiving an entrepreneurial orientation at least in terms of the relevant dimensions. Based on the views of Miller (1983) and Covin and Slevin (1991), entrepreneurial orientation consists of three dimensions, which are innovativeness, risk-taking, and pro activeness, whereas Lumpkin and Dess (1996) perceive entrepreneurial orientation to consist of five dimensions, which in addition to the ones of Miller (1983) are autonomy and competitive aggressiveness. The definition of Lumpkin and Dess is adopted in this study.There are two fundamental reasons for why a definition of entrepreneurial orientation based on the five dimensions of entrepreneurial orientation was chosen to be used in this dissertation. The first reason is that most of the studies of entrepreneurial orientation have adopted only the three dimensions. Thus, using this definition can make a difference. Moreover, in their analysis of the entrepreneurial orientation dimensions, Hughes and Morgan (2007) suggest that the introduction of the two newer dimensions may add value to entrepreneurial orientation. However the construct of innovativeness (in entrepreneurial orientation) may have similarities with the dependent variable (innovation) and hence the issue of co linearity may arise, as such, it's not included in the conceptualization of entrepreneurial orientation in this study.

The concept of innovation has been widely defined. Among them was Schumpeter (1942) who defined innovation as the commercial or industrial application of something new. In another opinion, Drucker (1985) defines innovation as a specific tool for entrepreneurs, the means by which they exploit change as an opportunity for different businesses. However, the Organization for Economic Cooperation and Development (OECD, 2005) redefined the term innovation more broadly than before as all types of changes in activities that could take place within an enterprise and aim to improve the enterprise's profitability, and hence adopted in this study. It implies the implementation of a new or significantly improved product, process, marketing method, or a significant organizational change.

Several studies have stressed upon the ties between entrepreneurial orientation and innovation. Harms et al; (2009), Lisboa et al (2013) and Wang \& Huang (2011) argue that entrepreneurship in itself is a pragmatic manner leading towards innovation and new venture establishment. As argued by Wiklund and Shepered (2005), entrepreneurial orientation refers to the tendency of a firm to indulge in innovative, proactive and risk prone ventures. This implies that if entrepreneurial orientation is prone towards innovation, there is a greater likelihood that the firm would embrace and manage innovation in more effective manner as compared to those firms where entrepreneurs are less innovative and risk aversive.

Entrepreneurial firms are better able to match their internal organization with the environment in dynamic competitive environment. They change and shape the environment and allocate resources to exploit uncertain business opportunities (Hakala, 2010). According to Kollmann \& Stockmann (2010), companies with a strong entrepreneurial orientation apparently will pursue innovation goals more effectively.

According to Madhoushi et al; (2011), entrepreneurial orientation both directly and indirectly through the knowledge management affectS innovation performance of SMEs. In line with Madhoushi et al (2011), Gunawan et al (2013) concludes significant relationship between entrepreneurial orientation and innovative performance. Similar result was also found by Wang and Huang (2011) which investigate the effect of entrepreneurial orientation and learning orientation on innovation in small and medium enterprises and established a significant correlation between entrepreneurial orientation and learning orientation with innovation using a data form a sample of 245 SMEs operating in Taiwan.Yang (2008) examined the impact of entrepreneurial orientation on performance of listed firms in the stock exchange and realized that entrepreneurial orientation has a direct effect on the performance of firms. In addition, Kevin et al (2011) in their study stated that high entrepreneurial orientation is closely related creating innovation that ultimately has a positive impact on performance.

A proactive firm is particularly adapt at seeking resources from outside its clusters, increasing the diversity and novelty of knowledge at its disposal. This inturns, enhances the potential number of new knowledge combinations that the firm can create, resulting in improved innovative performance. Lumpkin and dess (2001) found that proactiveness has the most signficant impact on firm performance in companies that operate in industries that are in early stages of their development. 
Other studies in small business settings which investigated the relationship between entrepreneurial orientation and performance Wang (2008) and Baba and Elumalai (2011) all found positive relationship between entrepreneurial orientation and performance. It is a common knowledge that SMEs need to have the ability to penetrate global market and significant relationship was concluded between internationalization of small firms and entrepreneurial orientation (Taylor, 2013). Thus, we can answer a resounding yes that small firm's innovation is influenced positively by entrepreneurial orientation, hence we hypothesize that: entrepreneurial orientation significantly and positively influenced firm innovation.

\section{Conceptual framework:-}

From the literature, causal linkage has been identified between entrepreneurial orientation and firm innovation. Figure 1 shows that firm innovation is an outcome variable of entrepreneurial orientation.

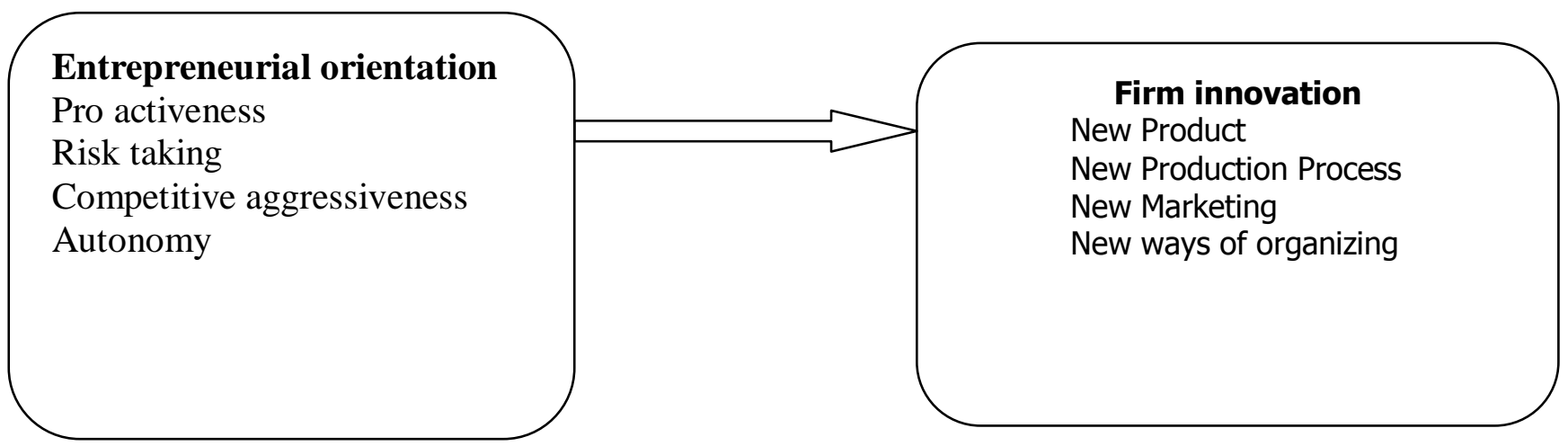

\section{Research design:-}

The research design adopted in this study was a cross-sectional survey. Questionnaires were used to collect data from 261 SMEs. Organizations must be in operation for at least five years at the time of the survey.Pearson linear correlation and linear regression analysis were used to investigate the relationship between entrepreneurial orientation and firm innovation.

\section{Measurement:-}

Using Lumpkin and Dess (1996)'s definition, entrepreneurial Orientation was measured as follows: Pro activeness consisted of five questions to measure firm's relations to market opportunities by seizing initiative in the market place.Risk bearing consisted of five questions to measure firm's tendency to venturing into unknown new market, committing a large portion of resources to ventures with uncertain outcomes. Competitive aggressiveness consisted of five questions to measure firm's reaction to competitive trends and demands that already exists in the marketplace. Autonomy consisted of five questions to measure independent action by an individual or team aimed at bringing forth a business concept or vision and carrying it through to completion.

Using OECD (2005), firm innovation was measured as follows: new product had five questions to measure the extent of the introduction of product that is new or significantly improved with respects to its characteristics. New production Process consisted of five questions to measure the production methods and support services that are intended to improve the quality, efficiency and flexibility of production. New marketing techniques consist of five questions to measure the new And improved marketing methods that involves changes in product design packaging, promotion, placement and new market entry. New organizational method had five questions to measure the extent of the implementation of a new organizational method in a firm's business practices, workplace organization and external relations.

\section{Validity:-}

Factor analysis was performed to confirm the construct validity of the instrument. The result, in Table 1 shows that $\mathrm{KMO}$ values for all constructs were acceptable $(\mathrm{KMO}>0.5)$. According to the accepted rule of thumb for measuring construct validity using KMO values as suggested by Field (2009), value of 0.900 and above is superb, 0.800 0.899 is great, $0.700-0.799$ is good, $0.600-0.699$ is mediocre, $0.500-0.599$ is acceptable, while below 0.500 is unacceptable. 
Table1:- Validity coefficients for all constructs.

\begin{tabular}{|c|c|c|}
\hline Construct & KMO value & Interpretation \\
\hline Proactiveness & 0.877 & Great \\
\hline Risk taking & 0.899 & Acceptable \\
\hline Competitive aggressiveness & 0.677 & Acceptable \\
\hline Autonomy & 0.693 & Great \\
\hline New Product & 0.867 & Great \\
\hline New Process & 0.885 & Great \\
\hline New Marketing method & 0.811 & Mediocre \\
\hline
\end{tabular}

Source: primary data (2016)

\section{Reliability:-}

The Cronbach's reliability test was performed to ascertain the reliability of the instrument. The result obtained from this analysis (Table 2) shows that Cronbach's Alpha values for all the variables were acceptable. According to George and Mallery (2003), Cronbach's value of 0.9- 0.99 is excellent, 0.8 to 0.899 is good, 0.7 to 0.799 is acceptable, 0.6 to 0.699 is questionable, 0.5 to 0.599 is poor, and below 0.5 is unacceptable.

Table 2:- Cronbach's Alpha value for constructs

\begin{tabular}{|c|c|c|}
\hline Construct & Cronbach's value & Interpretation \\
\hline Proactiveness & 0.806 & Good \\
\hline Risk taking & 0.895 & Acceptable \\
\hline Competitive aggressiveness & 0.701 & Acceptable \\
\hline Autonomy & 0.706 & Good \\
\hline New Product & 0.882 & Good \\
\hline New Process & 0.876 & Good \\
\hline New Marketing method & 0.805 & Good \\
\hline
\end{tabular}

Source: Field data (2015)

\section{Results:-}

Descriptive statistics for the study variables:-

The descriptive statistics for independent variables (pro-activeness, risk taking, competitive aggressiveness, and Autonomy,) are depicted in table 3. Similarly descriptive statistics for dependent variables (new product, new production process, new marketing method and new ways of organizing) were also depicted in table 3.

Table 3:- Descriptive Statistics for the study variables.

\begin{tabular}{|l|c|c|c|c|}
\hline Factor & Means & Standard deviation & Skewness & Kurtosis \\
\hline Proactiveness & 3.485 & 1.043 & 0.061 & -0.971 \\
\hline Risk taking & 2.121 & 1.092 & 0.633 & -0.396 \\
\hline Competitive aggressiveness & 3.182 & 0.872 & 0.175 & -0.111 \\
\hline Autonomy & 2.804 & 0.947 & 0.432 & -0.844 \\
\hline Entrepreneurial Orientation & $\mathbf{3 . 0 3 6}$ & 0.773 & 0.306 & -0.467 \\
\hline New Product & 3.348 & 1.302 & 0.141 & -1.126 \\
\hline New Production Process & 3.343 & 1.291 & 0.230 & -1.263 \\
\hline New Marketing Method & 3.378 & 1.193 & 0.220 & -1.092 \\
\hline New Ways of Organizing & 3.153 & 0.938 & 0.092 & -0.378 \\
\hline Firm Innovation & $\mathbf{3 . 3 0 6}$ & 1.319 & 0.299 & -1.208 \\
\hline
\end{tabular}

As depicted in table 3, the firms have moderate level of entrepreneurial orientation and innovation (mean $=3.036$ and 3.306 respectively). From table 3 , the factors can be considered normally distributed as the Skewness and Kurtosis values are close to 0. According to Field (2009), for data to be normally distributed, the values of both kurtosis and skewness should be close to zero. 


\section{Test of hypothesis:-}

The correlation of the independent variables with firm innovation was analyzed by performing Pearson's correlation and regression analyses. The values obtained from the coefficients vary from -1 to 1 . The sign of the values indicates if the correlation is rather negative or positive, and the size of the value provides indication about the strength of the correlation. A coefficient of 1.0 indicates a perfect positive correlation while -1 indicates a perfect negative correlation. According Cohen (1988), a correlation coefficient from 0 to 0.09 means no correlation from 0.1 to 0.29 means weak correlation, 0.3 to 0.49 means medium correlation and 0.5 to 1 strong correlation

Table 4:- The relationship between entrepreneurial orientation and firm innovation

\begin{tabular}{|l|l|l|l|l|l|}
\hline & $\begin{array}{l}\text { Pearson's correlation } \\
(\mathbf{R})\end{array}$ & Direction & Strength & $\begin{array}{l}\text { Coefficient of determination } \\
\left(\mathbf{R}^{\mathbf{2}}\right)\end{array}$ & Sig \\
\hline $\begin{array}{l}\text { Entrepreneurial } \\
\text { orientation }\end{array}$ & 0.524 & + & Strong & 0.275 & 0.000 \\
\hline
\end{tabular}

Source: Field data (2015)

Table 4 shows that entrepreneurial orientation is positively and strongly correlated to firm innovation $(\mathrm{R}=0.524)$. Furthermore, the coefficient of determination $\left(R^{2}=0.275\right)$ explains that entrepreneurial orientation is responsible for $27.5 \%$ of the variance in firm innovation. Since the sig value $(0.000)$ is less than 0.05 , the research hypothesis that entrepreneurial orientation has a significant and positive relationship with firm innovation was validated and with a valid relationship to innovation of $27.5 \%$

Table 5:- The relationship between the entrepreneurial orientation factors and firm innovation.

\begin{tabular}{|l|l|l|l|l|l|}
\hline Factors & $\mathbf{R}$ & Direction & Strength & $\mathbf{R}^{2}$ & Sig \\
\hline Pro activeness & 0.601 & + & Strong & 0.361 & 0.000 \\
\hline Risk taking & 0.511 & + & Strong & 0.261 & 0.000 \\
\hline $\begin{array}{l}\text { Competitive } \\
\text { aggressiveness }\end{array}$ & 0.210 & + & Weak & 0.044 & 0.318 \\
\hline Autonomy & 0.226 & + & Weak & 0.051 & 0.232 \\
\hline
\end{tabular}

Source: Field data (2015)

Table 5 indicates that pro activeness, and risk taking present a positive and strong correlation, with firm innovation while competitive aggressiveness and autonomy present a positive but weak correlation with firm innovation.

The sig values indicate that pro activeness, and risk taking have significant relationship with firm innovation (sig value $<0.05)$ and that proactiveness is responsible for $36.1 \%$ of the variance in firm innovation $\left(\mathrm{R}^{2}=0.361\right)$, while risk taking is responsible for $26.1 \%$ of the variance in firm innovation $\left(\mathrm{R}^{2}=0.261\right)$. On the other hand, the sig values for competitive aggressiveness and autonomy were 0.318 and 0.232 which were all greater than 0.05 meaning that they have no significant relationship with firm innovation and they only explains $4.4 \%$ and $5.1 \%$ of the variation in firm innovation respectively $\left(\mathrm{R}^{2}=0.044\right.$ and 0.051 respectively).

\section{Discussions:-}

It's indicated in table 3 that positive and strong correlation exists between entrepreneurial orientation and firm innovation. This means adoption of entrepreneurial behaviors by firms will help them to enhance their innovation performance. This finding is in line with authors like Zahra and Covin (1999), Madhoushi et al (2011), Dess et al (2010), Salavou et al (2004) and Gunawan et al (2013). This means that there is a growing body of evidence to suggest that a positive association exists between a firm's entrepreneurial orientation and firm innovation.By investing in entrepreneurial orientation, managers allow for the discovery and experimentation of new ideas and features which facilitate firm innovation.

An analysis of the implications of individual dimensions shows that the dimension of entrepreneurial orientation contributed to firm innovation in different levels. Proactiveness, and risk taking were found to predict firm innovation significantly. The significant association found betwee proactiveness, and risk taking with innovation confirms the previous findings of Hult et al (2004), Madhousi et al. (2011) and Hughes and Morgan (2007) about the positive significant connection beween proactiveness and risk taking with firm innovation. However it was found that competitive aggressiveness and autonomy were not significant predictors of firm innovation in this study. These 
results support the view of Lumpkin and Dess (1996) as well as Hughes and Morgan (2007) in that all the dimensions of entreprenuial orientation do not contribute to firm innovation performance at least in every situation and setting. The positive and significant impacts of entrepreneurial orientation onfirm innovation may be related to the significance the firms attach to that concepts. Therefore paying attention to them is one of the most significant factors in achieving competitive advantage.

The results of this study indicate that entreprenuerial orientation is a precursor of firm innovation. Openness to new ideas, proactiveness and risk tolerance can act as a springboard to firm innovation. Thus firms are encouraged to adopt entrepreneurial orientation in order to enhance innovation. The importance of entrepreneurial orientation is that it enables firms to strategically position themselves to exploits opportunities in turbulent markets. Wiklund and shepered (2005) argue that entrepreneurial orientation can be used as a means to over come limitations imposed by limited access to capital and environment where new opportunities are scarce. In other words, it is under these circumstances that firm managers can benefit from been inovative, thus creating and developing products, taking proactive action and engages in fairly risky new projects, hence differentiating their enterprises from their competitors.

\section{Conclusion:-}

The main objective of this study was to explore the relationship beween entrepreneurial orientation, and innovation of firms. Based on the findings and discussions, it's concluded that entrepreneurial orientation is a significant predictor of firm innovation. This means the more the firms go entrepreneurial, the more they will be able to seek for new opportunities and efficiently exploit them. It's also concluded that pro activeness contribute most to firm innovation compared to other dimensions of entrepreneurial orientation. Firms should therefore concentrate on pro activeness which seem to lead to higher innovation than adopting entrepreneurial orientation as a whole

\section{Reference:-}

1. Baba, R. and Elumalai, S. (2011). Entrepreneurial orientation of SMEs in Labuan and its Effects on performance. FEB working paper series No.113.

2. Covin, V. G. and Slevin, D. P. (1991). A conceptual Model of Entrepreneurship as Firm Behavior. Entrepreneurship Theory and Practice, Vol. 4, No. 6.

3. Covin, J.G. and Lumpkin, G.T. (2011). Entrepreneurial orientation theory and research: reflections on needed construct. Entrepreneurial theory andpractice, (35) 855-872.

4. Dess, G. G; Lumpkin, G. T. and Esner, A. B. (2010). Strategic Management: Text and Cases MCGraw Hill. New York, U.S.A.

5. Drucker, P.(1985). Innovation and Entrepreneurship. Hutchinson. London.

6. Field, A. (2009). Discovering statistics using SPSS.Sage Publications. Los Angeles, U. S. A.

7. George, D. and Mallery, P. (2003). SPSS for Windows step by step. A sample Guide and reference. Alyn and Bacon. Boston, U. S. A.

8. Gunawan, T; Jacob J. and Duster, G. (2013). Entrepreneurial Orientation and Network Ties: Innovative performance of SMEs in an Emerging Economy Manufacturing Cluster. Maastrict School of Management Working Paper No. 2013/23.

9. Hakala, H. (2010). Strategic orientation in management literature; three approaches to understanding the influence between market technology, entrepreneurial and market orientations.Journal of Management review.

10. Harms, R. Schulz, A; Krauss, M. and Fink, M.(2009). The Conceptualization of Opportunity in Strategic Management. Research International Journal of Entrepreneurial Venturing, 1(1)57-71.

11. Hughes, M. and Morgan, R.E. (2007). Deconstructing the relationship between entrepreneurial orientation and business performance at the embryonic stage firm growth. Indus market manage 36: 652-661.

12. Hult, G.T.M. Hurley, R.F. and Knight, G. A. (2004), Innovativeness.Its antecedents and impact on business performance.Industrial Marketing Management 33(5) 429-438.

13. Lisboa, A. Skerness, D. and Lagos, C. (2010). Entrepreneurial Orientation Innovative Capabilities and Performances Outcomes: An empirical investigation. Apartado, Portugal.

14. Lumpkin, G. T. Dess, G. G. (1996). The role of entrepreneurial orientation in stimulating effective corporate entrepreneurship. Academy of Management Executive, 19(1)147-156.

15. Madhoushi, M. T; Sadati, A. and Delvani, H. (2011). Entrepreneurial Orientation and Innovation Performance: The Mediating Role of Knowledge Management. Asian Journal of Business Management, 3(4)310-316.

16. Miller, D. (1983). The Correlate of Entrepreneurship in Three Types of Firms. Manage, 29(7)770-791. 
17. Miller, D. (2011). A Reflection of Entrepreneurial Orientation Research and Some Suggestions for the Future. Entrepreneurship Theory and Practice, 35(6)873-894.

18. Organization for Economic Co-operation and Development (OECD) (2005).Oslo manual: Guidelines for collecting and interpreting innovation data ( $3^{\text {rd }}$ edition). Paris, France.

19. Schumpeter, J.A. (1942).Economic theory and entrepreneurial History. Exploitations in Enterprises Havard

20. University Press. Cambridge, U.S.A.

21. Taylor, P.(2013).The effect of entrepreneurial orientation on the internationalization of SMES in developing countries. African Journal of Business Management, 7(19)1927-1111937.

22. Wang, C.L. (2008).Entrepreneurial orientation, learning orientation, and firm performance. Entrepreneurship Theory and Practice, 635-657.

23. Wang,Y.and Huang,S. K. (2011). Entrepreneurial Orientation, Learning Orientation and Innovation in Small and Medium Enterprises. Procedia social and Behavioral science,24(2011)563-570.

24. Wiklund,J. and Shepherded.(2005). Entrepreneurial orientation and small business performance. A Configurational Approach. Bus Venturing, 20(1) 71-91.

25. Yang, C.W. (2008). The relationships among leadership style, entrepreneurial orientation and business performance. Manage Glob. Trans. 6(3) 257275.

26. Zahra,S. A.(1993).Conceptual Model of Entrepreneurship as Firm Behavior. A Critique and Extension.

27. Entrepreneurship Theory and Practice, 14(4)5-22.

28. Zahra, S. and Colvin, J. (1999). Contextual influence on the corporate entrepreneurship performance relationship: a longitudinal analysis. Journal of Business Venturing; 10, 43-58. 